Revista Signos

2009, 42(71)

317-332

\title{
De la función metalinguiística al metalenguaje: Los estudios sobre el metalenguaje en la linguiística actual
}

\author{
Óscar Loureda \\ Universidad de Heidelberg \\ Alemania
}

Resumen: En este trabajo llevo a cabo un breve recorrido por los hechos metalingüísticos que constituyen un complemento actual de aquella orientación primera de los estudios que tiene su base en los conocidos trabajos de Jakobson. Se trata de manifestaciones de la dimensión reflexiva del lenguaje que: a) o 'hablan del' lenguaje (discursos sobre el lenguaje); b) o presentan distinciones en el ámbito 'real' del lenguaje (léxico, fraseología, etc.); c) o son trozos de lenguaje presentados en el texto sobre los que se habla (uso metalingüístico); d) o son signos lingüísticos que para ser comprendidos por completo explícitamente necesitan la 'objetivación' de otros signos (enunciados-eco). Además de mostrar una tipología de los hechos, propongo una clasificación funcional dentro de una teoría del lenguaje 'realista'.

Palabras Clave: Metalenguaje, metadiscurso, reflexividad del lenguaje.

Recibido:

5-I-2009

Aceptado: 30-IV-2009
Correspondencia: Óscar Loureda (oscar.loureda@iued.uni-heidelberg.de). Cátedra de Ciencias del Lenguaje y Traducción: Seminario de Español para Traducción e Interpretación, Universidad de Heidelberg. Plöck 57a, 69117, Heidelberg, Alemania. 


\title{
From metalinguistic function to metalanguage: Studies of metalanguage in current linguistics
}

\begin{abstract}
In this article I will draw a short overview over the metalinguistic facts that form a complement to Jakobson's early works. It will deal with the manifestations of the reflexive dimension of language, which a) either 'speak about' language (discourse about language); b) or present distinctions on the 'real' level of language (lexicon, phraseology etc.); c) are pieces of language represented in texts that are spoken about (metalinguistic use); d) or are linguistic signs that in order to be understood completely and explicitly need the 'objectivation of other signs (eco utterances). Apart from presenting a typology of the facts, I will propose a functional classification within a 'realistic' language theory.
\end{abstract}

Key Words: Metalanguage, metadiscourse, language reflexivity.

\section{INTRODUCCIÓN}

Con una rápida revisión de la bibliografía podemos advertir que el conjunto de hechos que se consideran bajo el concepto de 'metalenguaje' es ya, lejos de la relativa homogeneidad inicial, notablemente plural. Se someten a examen, por ejemplo, refranes y dichos que predican algo del lenguaje o del hablar, como 'Donde dije digo, digo Diego', 'Al pan, pan, y al vino, vino' o 'A buen entendedor, pocas palabras bastan'; también se considera otro tipo de discurso, no histórico o no tradicional, como 'Ese quizás me sonó a un no' o Sócrates es un nombre, bien en lo que concierne a las propiedades semióticas de las unidades 'mencionadas', bien en lo que concierne a la predicación misma (= al comentario propiamente dicho), como en el análisis ('metapragmático', se dice) que implica la famosa frase de Voltaire: "Cuando un diplomático dice un 'sí' quiere decir un 'quizás', cuando dice un 'quizás' quiere decir un 'no', y si dice un 'no' no es un diplomático"; o en la identificación/interpretación de los valores que conlleva la célebre anécdota del rey Carlos V, quien una vez declaró que él hablaba en español con Dios, en italiano con los hombres, en francés con las mujeres y en alemán (probablemente, en flamenco) con los caballos.

Se habla de 'metalenguaje' también en el ámbito del léxico, para referirse a numerosos términos con que las lenguas distinguen formas de hablar, como 'mentir', 'acusar', 'susurrar', 'declarar', 'decir' o 'conversar'; cualidades de las personas en tanto que hablantes, como 'locuaz', 'badulaque' o 'bienhablado', o de los discursos como tales, por ejemplo, 'lapidario', 'conciso', ‘escueto' o ‘sucinto'; o modos de presentarse los textos, como ‘explicación', ‘charla', ‘comentario’, ‘conversación', ‘noticia’, ‘justificación’, ‘diálogo', ‘discusión’, ‘carta’, etcétera.

Referencias a lo metalingüístico se hallan, asimismo, en estudios sobre el 'discurso repetido' 
(Coseriu, 1981), en concreto en estudios sobre aquel discurso repetido que no puede reducirse a textos, sino a unidades de nivel inferior, esto es, en unidades fraseológicas equivalentes a sintagmas e incluso a palabras Coseriu (2007) (véase también la Nota 1):

"hablar como un papagayo, hablar como un descosido, hablar por los codos, hablar más que un sacamuelas; hablar en plata; hablar/decir en cristiano, hablar uno en romance, hablar en román paladino; hablar cara a cara, decir a los cuatro vientos, decir(se)lo (incluso) al lucero del alba, decir para sí, decir entre nosotros" (Coseriu, 2007: 112).

Más aún, a la investigación gramatical, además de las estructuras metalingüísticas que se emplean en el nivel (sub)oracional, le resultan interesantes los procedimientos regulados específicamente por cada idioma que operan en el nivel del texto. Y además de hacer explícita la gramática del uso metalingüístico, resulta particularmente importante dar cuenta de sus empleos y motivaciones en el hablar corriente (Vigara, 1992). Muchas veces, en efecto, se emplean los signos relacionándolos conscientemente con otros signos, de la propia lengua o de otra, o con otros textos o fragmentos de textos más o menos conocidos: creamos, en una palabra, 'evocaciones.' En los chistes este recurso metalingüístico sirve para generar desenlaces cómicos, por ejemplo en ‘Cómo se llama el director de una clínica japonesa? Dr. Sekuro Ketekura’. ‘¿Y el jefe de urgencias de esa misma clínica? Dr. Takurado Yamimo'. En estos casos, en la configuración de los signos se imita la forma sonora de los significantes del japonés, o más bien lo que culturalmente se interpreta como la forma sonora del japonés. Análogos procesos se desencadenan en la modificación de frases hechas, en la publicidad, como en 'No compre sin Thom ni Son (por sin ton ni son)' o en 'Familia Philips, familia feliz'; o también en traducciones literales, como en 'Las aves del César murieron por falta de salud', traducción de 'Ave Cesar morituri te salutant', feliz, por ejemplo, desde el punto vista de un chiste.

Existe, finalmente, y por ahora sin ánimo de ser exhaustivo, distintos hechos y procedimientos propiamente 'metadiscursivos'. Los denomino de este modo porque solo caben en el nivel del discurso (= en el texto o en el hablar) y porque exigen, tanto en la fase de construcción como en la de interpretación, la puesta en marcha de una conciencia lingüística reflexiva (Lucy, 1993). Me refiero, por ejemplo, a la atenuación y a la intensificación del decir y de lo dicho -nótese la diferencia entre 'Lee este trabajo mío y dime qué te parece' y 'Soy un pesado, ya sé, pero si pudieras, y digo solo si pudieras, leerme este trabajito y decirme qué te parece'-, o a los tipos de intertextualidad, como la cita o la ironía- enunciados-eco, como la ironía: cuando en la película ‘El padrino' el protagonista dice: “Mi padre fue la segunda vez con Luca Brasi y le hizo una oferta que no pudo rechazar", todos entendimos el enunciado irónico... y con ello, de qué clase de 'oferta' se trataba. De todos los hechos y procedimientos metadiscursivos se ocupa la pragmática, o la 'lingüística del texto', pues tienen lugar en el hablar, aunque en cierta medida pueden estar determinados por la gramática textual de cada idioma'. 
Por lo tanto, se ha producido una extensión en los estudios sobre el metalenguaje. Una extensión doble, incluso: cuantitativa y cualitativa. Los tratados que inauguran el estudio de lo metalingüístico enseñan que en el hablar sobre la realidad y en el hablar sobre el lenguaje los signos se emplean de distinta manera. La lógica escolástica medieval estableció la distinción entre significatio, el concepto, y suppositio, el modo en que los nombres hacen referencia a las cosas y agregó a la lógica de Aristóteles, y de sus famosos continuadores Porfirio y Boecio, un nuevo capítulo, de terminorum proprietatibus, o de las propiedades de las palabras. La doctrina de la suppositio empleó este término para denotar los varios modos regulares en que un nombre puede usarse para denotar objetos diferentes (Urban, 1952). Los modos en que un signo se aplica a las cosas deslindan ante todo lo que pertenece al lenguaje de lo que no (San Agustín, De Magistro, 1970). A estas modalidades de referencia Shyreswood (1937) las denomina, respectivamente, suppositio materialis y suppositio formalis:

"Est igitur suppositio quaedam materialis, quaedam formalis. Et dicitur materialis, quando ipsa dictio supponit vel pro ipsa voce absolute vel pro ipsa dictione composita ex voce et significatione, ut si dicamus: homo est dissillabum, homo est nomen. Formalis est, quando dictio supponit suum significatum" (San Agustin, 1970: IV, 7-8).

La lógica neopositivista del Círculo de Viena recupera estas distinciones porque las necesita para construir un lenguaje de orden superior y formalizado que fundamente y sea capaz de interpretar el valor de verdad de las proposiciones del lenguaje científico:

"We have to use two different languages in discussing the problem of the definition of truth and, more generally, any problem in the field of semantics. The first of these languages is the language which is 'talked about' and which is the subject matter of the whole discussion; the definition of truth we are seeking applies to the sentences of this language. The second is the language in which we 'talk about' the first language, and in terms of which we wish, in particular, to construct the definition of truth for the first language" (Tarski, 1944: 349)².

Aunque fue Hjelmslev (1971), en sus 'Prolegómenos a una teoría del lenguaje', quien transvasó a la lingüística el término 'metalenguaje' (o como él prefiere, 'metasemiótica'), la expresión 'función metalingüística' o 'glosadora' procede de los trabajos de Jakobson (1984) que toma el concepto de la lógica, pero lo extiende y supera. Por una parte, concibe el metalenguaje en relación con las funciones o dimensiones del lenguaje3: "Cuando el destinador y/o el destinatario quieren confirmar que están usando el mismo código, el discurso se centra en el código: entonces realiza una función metalingüística" (Jakobson, 1984: 357); y, por otra, no cree que se trate solamente de una herramienta 'científica' (del lenguaje de lógicos o lingüistas) y 'formalizada' 
(= artificial) para la descripción del lenguaje-objeto: "También juega un papel importante en el lenguaje de todos los días". En síntesis, la principal contribución de Jakobson (1984) reside en la interpretación del 'lenguaje descriptivo' de la lingüística como un metalenguaje ${ }^{4} \mathrm{y}$, sobre todo, en el reconocimiento de la presencia de operaciones metalingüísticas en el llamado lenguaje 'natural' como un recurso de los hablantes para objetivar (= para transformar en objeto del decir) los signos.

Después de Jakobson (1984), y sobre todo después del trabajo de Rey-Debove (1997), la lingüística abandonó en buena medida la idea de que el metalenguaje constituye un lenguaje formalizado; de hecho 'juega un papel importante en el lenguaje de todos los días' ${ }^{5}$. Desde entonces ha desarrollado, por un lado, la investigación en campos ya explorados desde el punto de vista de la lógica, como son la organización del modo de hablar sobre lo lingüístico (esto es, las relaciones entre el lenguaje primario y metalenguaje) y las propiedades de los signos sobre los que se predica algo (= los signos 'mencionados', 'autónimos' o ‘usados metalingüísticamente’ $)^{6}$, y, por otro lado, ha puesto de relieve otras manifestaciones de lo metalingüístico que confirman la importancia de la dimensión reflexiva del lenguaje ${ }^{7}$.

En este trabajo realizo una breve revisión de hechos metalingüísticos que constituyen un complemento de esa orientación inicial de los estudios. Se trata de manifestaciones del metalenguaje o de la dimensión reflexiva del lenguaje ('lenguaje en el lenguaje' o 'lenguaje sobre el lenguaje'): a) o 'hablan del' lenguaje (discursos sobre el lenguaje), b) o presentan distinciones en el ámbito 'real' del lenguaje (léxico, fraseología, etc.), c) o son trozos de lenguaje presentados en el texto sobre los que se habla (uso metalingüístico), d) o son signos lingüísticos que para ser comprendidos por completo explícitamente necesitan la 'objetivación' de otros signos (enunciados-eco). Además de mostrar una rápida tipología de los hechos (muy sintética, eso sí) intentaré proponer su clasificación funcional en una teoría del lenguaje realista. Esta teoría del lenguaje es de Coseriu (1973). Una de las más difundidas distinciones Coseriu, basada en planteamientos clásicos, separa tres niveles en el hablar: el 'universal', el 'histórico' y el 'individual'. En su 'Competencia lingüística' (Coseriu, 1992) explica que el lenguaje nace de una capacidad general del hombre para expresarse; reconoce, además, que se acompaña, a veces, de una actividad gestual que incide en el contenido de lo que se expresa; e indica, asimismo, que presenta una dimensión puramente biológica. Pero, subraya, ninguno de los tres planos anteriores aporta la verdadera y esencial dimensión del hablar: también en los animales se aprecia cierta capacidad de expresión, hábitos gestuales y una disposición psíquico-física para producir y captar mensajes. El lenguaje (casi huelga decirlo, humano) es cualitativamente diferente por su dimensión cultural. Coseriu (1992: 86) lo define en este sentido como:

"una actividad humana universal que es realizada individualmente en situaciones de- 
terminadas por hablantes individuales como representantes de comunidades lingüísticas con tradiciones comunitarias del saber hablar".

Por lo tanto, el hablar es una actividad 'universal', común a todos los hombres; también es 'histórica', pues quien habla emplea, por lo menos, una lengua; y es 'individual' porque habla un individuo (también en el diálogo, alternativamente) y porque tiene lugar en un 'entorno' determinado. En cada uno de estos niveles existe una manifestación de lo metalingüístico.

\section{Tipología del metalenguaje: El metalenguaje del nivel universal}

Existe, en primer lugar, un metalenguaje universal, propio del lenguaje mismo, no de las lenguas o del discurso. El uso metalingüístico del lenguaje primario, en efecto, es una propiedad universal del lenguaje en general y en sí no puede vincularse a las lenguas históricas ${ }^{8}$, aunque es cierto que su funcionamiento puede estar (y de hecho normalmente lo está) en parte determinado por la gramática de las lenguas; y no se trata de una posibilidad universal del lenguaje porque se haya comprobado su existencia en todas las lenguas (= porque se haya deducido de las lenguas y se haya generalizado), sino porque se constituye racional y necesariamente como propiedad previa a todo modo histórico de hablar. En tanto que posibilidad universal, se asienta sobre la 'no inefabilidad'. Y como mediante el lenguaje puede hablarse de todo, entonces cualquier elemento del lenguaje primario (= como 'cosa' o como parte de la realidad) puede convertirse ('reflexivamente', se dice a menudo') en objeto del decir. Se trata, en suma, de una especie de mise en abyme como posibilidad del lenguaje como tal, según se muestra en la Figura 1, adaptando el esquema de Bühler (1967):

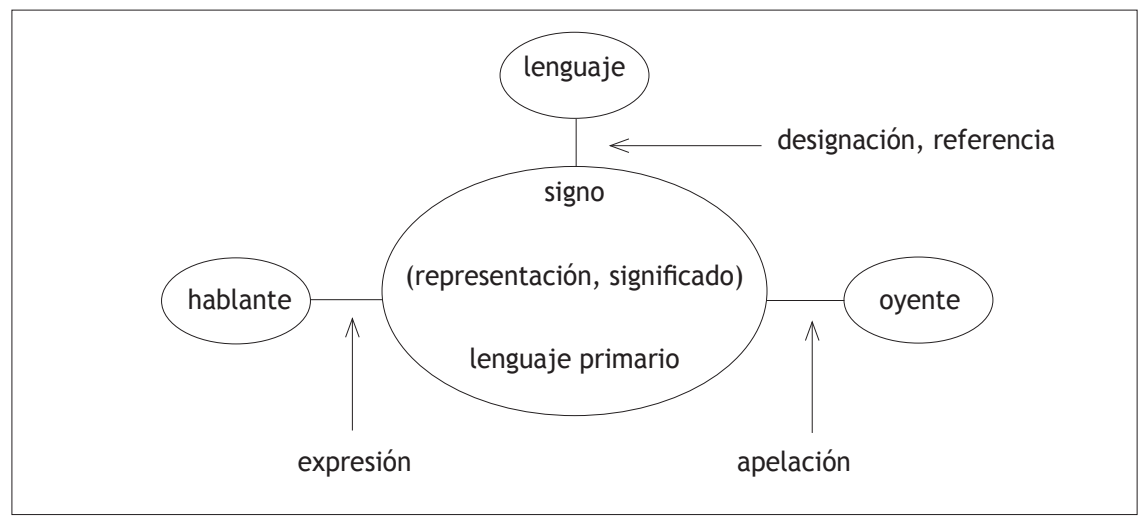

Figura 1. El signo según Karl Bühler. 
La capacidad del lenguaje para hablar de sí mismo en el discurso (por ejemplo, 'En lugar de tienes que hacer podrías haber dicho deberías hacer y no hubieras parecido tan brusca o en 'Sócrates es un nombre') provoca que, a la hora de convertir algo en objeto de una predicación, se distinga entre lo lingüístico y lo no lingüístico. Hay, por una parte, un modo de hablar en el cual el lenguaje primario tiene el mundo no lingüístico por objeto (por ejemplo, en 'Juan no es muy amable') y hay, por otra parte, un modo de hablar que solamente habla del lenguaje primario. Quiere decirse, siguiendo una vieja idea de Coseriu, que la llamada por Jakobson 'función metalingüística' del lenguaje no es más que un caso especial de la función que Bühler denomina 'objetiva' (= designativa), de lo que en la terminología de Jakobson se llama función 'referencial'10. En el fondo, se trata de la recuperación del deslinde efectuado por la lógica medieval a través de la doctrina de las suppositiones.

En un texto como 'Pronunció un hasta pronto que sonó a despedida definitiva' hay, al menos, dos aspectos de lo metalingüístico reseñables: por una parte, la predicación, es decir, el hablar de un objeto de la realidad que se presenta como hecho lingüístico; y, por otra, la unidad misma sobre la que se dice algo, es decir, el segmento de lenguaje 'autónimo' o 'mencionado' o 'usado metalingüísticamente'. Esta propiedad de referirse a un signo que a la vez que signo es una parte de la realidad misma, es una propiedad universal, aunque puede estar en parte determinado por la gramática de las lenguas ${ }^{11}$, comprobable en el discurso; y puede referirse a cualquier trozo de lenguaje (= es universal en su extensión), como palabras 'Veremos es primera persona del plural/Eso de veremos suena mal'; morfemas: 'El sufijo -ble genera adjetivos deverbales'; sílabas: 'La m con la a, ma; la m con la e, me...; la mera agrupación de letras: 'Al escribir has puesto uir y no tir'; los segmentos superiores a la palabra: 'Ese yo me parece que es un anacoluto que, pese a su agramaticalidad, tiene una función pragmática'; unidades de otras lenguas: 'Creo que no eres capaz de hablar en italiano sin emplear en cada frase mah, beh, boh o neh'; e incluso trozos del lenguaje de ninguna lengua histórica: 'Ahora todos los jóvenes dicen grijander, fistro y peich para imitar a Chiquito'.

Como expliqué en un trabajo anterior, complementario de este (Loureda, 2006), las unidades usadas metalingüísticamente son unidades usadas en el discurso (todo hecho del lenguaje puede ser 'usado'); formas meras y concretas: hechos físicos, sustancia; signos-símbolo versus signos (= palabra significativa versus mera palabra); no son significativas ("no tienen sinonimia ni traducción', Rey-Debove, 1997; Ulrico, 1997); no designan; 'están' en el hablar (= entes); y como tales formas no pertenecen a categoría verbal alguna, es decir, que en sentido estricto no son sustantivos, sino unidades con 'sustantividad' (= formas con existencia real, independencia e individualidad).

Un problema distinto -que solo puedo considerar muy rápidamente- es el de la distinción entre unidades usadas metalingüísticamente y unidades del lenguaje primario. Cabe plantear aquí la 
existencia de un continuo, que va desde unidades 'objetivadas' completamente (por ejemplo: 'Veo' viene de 'video') a unidades no metalingüísticas ('Te veo'), pasando por un centro en el que unidades y procedimientos del discurso, como evidenciales u operaciones de reformulación, a través de la proyección sintagmática precisan de la toma de conciencia 'objetiva' o 'reflexiva' de algún tramo del discurso, como se ve en la Figura 2:

\begin{tabular}{|c|c|c|c|}
\hline & & & metalenguaje \\
\hline \multirow{2}{*}{\multicolumn{3}{|c|}{$\begin{array}{l}\text { no te 'miro' } \\
\text { sino que te 'veo' }\end{array}$}} & 'veo' viene de 'video' \\
\hline & & & \\
\hline \multicolumn{2}{|c|}{ lenguaje primario } & & \\
\hline
\end{tabular}

Figura 2. El continuum entre el lenguaje primario y el metalenguaje.

\section{Tipología del metalenguaje: El metalenguaje del nivel idiomático}

Un segundo tipo de hechos metalingüísticos pertenece a la metalengua. En efecto, las lenguas disponen de términos mediante los que presentan el lenguaje como 'conocido' (= una unidad pensada diversa), según Dimter (1981), Wierzbicka (1987), Escobedo (1992), Loureda (2003). En el español, por ejemplo, hay voces usuales, no terminológicas, que significan formas de hablar, como 'mentir', 'acusar', 'susurrar', 'declarar', 'decir' o 'conversar'; modos de realizar los actos de habla, presentes en adverbios y locuciones como 'francamente', 'sinceramente' o 'lisa y llanamente'; cualidades de las personas en tanto que hablantes (como 'locuaz', 'dicharachero', 'badulaque', 'bienhablado', 'mordaz', etcétera) o de los discursos como tales (por ejemplo, 'lapidario', 'obvio', 'conciso', 'escueto', ‘sucinto', 'solemne' o 'macarrónico'); modos de presentarse los textos, como 'explicación', 'observación', 'apunte', 'aviso', 'charla', 'comentario’, ‘traducción', ‘murmuración', ‘conversación', ‘noticia’, 'rumor’, 'paráfrasis', 'receta’, ‘justificación', ‘diálogo', 'discusión', 'poema’, 'carta’, etcétera. En el ámbito más estrecho de la terminología lingüística, también hay un conjunto de voces nomencladoras como 'monema', 'oración', 'acto ilocutivo', 'sílaba', 'texto', 'superestructura', etc.

Dentro de la metalengua, pero es ese ámbito específico tradicionalizado que es la fraseología, también existe una serie de unidades que son metalingüísticas en al menos dos sentidos: primero, porque algunas de las expresiones funcionan como marcadores 'metadiscursivos' (son unidades fraseológicas al servicio de la gramática textual (idiomática) y de la dimensión sintagmática del texto ${ }^{12}$, como 'es decir', ‘mejor dicho' o 'dicho de otra manera', 'dicho sea de 
paso', 'dicho sea entre paréntesis' o 'todo hay que decirlo'; y segundo, porque, al igual que los refranes metalingüísticos y las unidades del léxico metalingüístico, la fraseología muestra una lingüística intuitiva implícita ${ }^{13}$, como en las unidades ya anteriormente citadas: 'hablar para el cuello de la camisa', 'hablar por hablar', 'jurar en arameo', 'prometer el oro y el moro', 'echar la lengua a paseo', 'tirar de la lengua', 'cantar a alguien las cuarenta', 'tener un pico de oro' o 'no tener pelos en la lengua'. Como unidades que muestran una lingüística implícita son objeto de la fraseología y de la etnolingüística idiomática; como marcadores metadiscursivos, son objeto de la gramática del texto, en particular, y del análisis del discurso en general: se trata, en este último caso, de estudiar las funciones textuales que introducen en el hablar, como reformulación ('mejor dicho', 'es decir', 'vale decir', 'digo', 'qué digo', 'quiero decir', 'dicho de otra manera', 'dicho en otras palabras', 'por no decir'), digresión ('dicho sea de paso', 'dicho sea entre paréntesis'), ponderar o afirmar enfáticamente algún segmento del enunciado ('que ya es decir', 'y ya es decir', 'no digamos', 'se dice pronto'; función organizadora en el discurso, concretamente de cierre: 'no se hable más', 'no hay más que hablar', 'he dicho'; expresiones que manifiestan el carácter meramente aproximativo o parcialmente inadecuado con que se emplea el segmento lingüístico al que acompañan: 'como aquel que dice', 'digamos', 'por decirlo así, etc.

Alguna de estas partículas idiomáticas (locuciones, adverbios, etc.) funcionan como 'comentarios oracionales':

‘Según dicen, todo ha salido bien’ (modalidad epistémica, fuente del mensaje)

o como comentarios del alcance del acto de habla:

'Te lo digo en serio, me voy del trabajo'.

'Creo que el comentario ese de crías va con segundas';

\section{Tipología del metalenguaje: El metalenguaje del hablar}

Un tercer tipo de hechos -y de hechos muy diversos- pertenece esencialmente al hablar (para el caso, discurso, texto). En efecto, aquí se producen, por una parte, hechos del 'decir sobre' el lenguaje. La competencia lingüística es un saber técnico: los hablantes saben cómo emplear la facultad del lenguaje, cómo hablar un idioma con sus variedades internas y cómo construir discursos en distintas circunstancias atendiendo al tema que se pretende tratar, al oyente y al contexto. Pero también, muy a menudo, el hablante se convierte en 'lingüista' e intenta valorar algún hecho lingüístico, es decir, que intenta 'hablar de' su lenguaje o del de los demás. Estos discursos metalingüísticos no son intrascendentes, pues pueden influir indirectamente en el comportamiento lingüístico: 
“Los hablantes como 'hablantes' [como meros usuarios] no planifican sus lenguas, pero como 'lingüistas' pueden -a través de la reflexión metalingüística y [como consecuencia de ello] usando o no ciertas formas- influir en su propio hablar. Si la finalidad de su intervención corresponde a la de otros hablantes, puede tener consecuencias para la evolución de la lengua" (Kabatek, 2000: 61).

En síntesis, los juicios que emiten los hablantes sobre su hablar, el hablar de los demás, sobre los usos de una unidad léxica o sobre cualquier otro aspecto del lenguaje pueden conllevar cambios en la lengua, como se ve en la Figura 3.

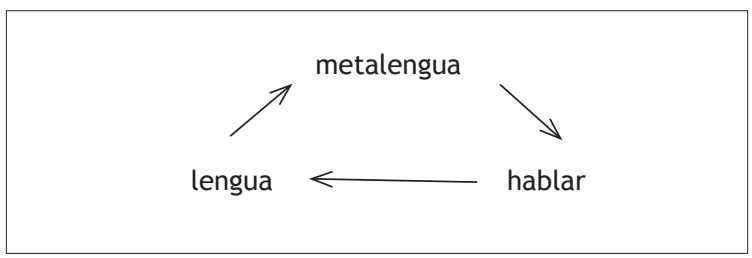

Figura 3. La interacción entre lengua y metalengua.

En este sentido hay textos individuales (= responsabilidad de un hablante) en los que 'dice algo' del lenguaje o de cualquiera de sus aspectos. Si el discurso metalingüístico puede modificar la lengua mediante las actitudes colectivas que es capaz de generar, la investigación de las 'actitudes' que se manifiestan en dichos actos de habla es relevante para la lingüística; en concreto, para la sociolingüística.

No obstante, también hay discursos 'históricos': manifiestan ciertos juicios y actitudes que forman parte de la memoria textual colectiva de una comunidad dada, y recogen valores y normas intuitivamente fijadas sobre el hablar y el lenguaje que solo son atribuibles a una comunidad lingüística como tal (Manero, 2005). En español, por ejemplo, existen alrededor de 2.500 refranes que muestran distinciones no solo de aspectos propiamente verbales, sino también de aspectos lingüísticos, en todos los sentidos posibles. Se presentan, en efecto, normas generales del hablar: 'Hablar sin ton ni son es saltar como el cigarrón'; 'Hablar sin reflexionar es tañer sin templar'; sobre la variación idiomática: 'En cada villa, su maravilla'; 'y en cada lugar, su modo de hablar'; sobre elementos kinésicos y proxémicos: 'Hable la lengua y estén las manos quedas'; sobre aspectos físicos o biológicos del lenguaje: 'Quien habla hueco, tiene el cerebro seco'; sobre el contenido, como la exigencia de claridad: 'Al pan, pan, y al vino, vino'; la exigencia de síntesis y brevedad: 'Lo bueno, si breve, dos veces bueno'; sobre dimensiones pragmáticas y extralingüísticas del discurso: sobre relaciones entre los interlocutores manifestadas a través de 
un acto de habla: 'A buen entendedor, pocas palabras bastan'; sobre la adecuación al contexto: 'Cuando callar, callar, y cuando hablar, hablar'; sobre las cualidades intelectuales o morales del hablante: 'Cual es cada uno, tales son sus palabras' o 'Al buey por el asta, y al hombre por la palabra', etc.

Por otra parte, en el plano del discurso también hay una serie de hechos que asocian en el hablar (= en el nivel del texto) la información extralingüística (= el conocimiento de las cosas) a la dimensión lingüística del signo (= significados y significantes) para servir a ciertos fines, como publicitarios o humorísticos. Estos procedimientos son relaciones del signo, es decir, que son un hecho semiótico; pero son, desde el punto de vista de la finalidad, relaciones del signo en el discurso que sirven para crear efectos de sentido. Entonces, su estudio corresponde a la lingüística del texto, que, como hermenéutica del sentido, trata de establecer el registro "de los tipos comprobados o posibles de sentido y de los procedimientos que suelen conllevarlos, o los han conllevado en discursos ya experimentados" (Coseriu, 2007:2).

Particularmente interesantes son los casos de evocación construida sobre la base de un segundo texto (eco), como en el caso de la intertextualidad: así sucede en el caso de la 'alusión' que del célebre texto de Kennedy: "Ich bin ein Berliner" hace el presentador de televisión alemán Johannes B. Kerner en la publicidad de las líneas aéreas Air Berlín: "Ich bin ein Air Berliner". También sirven como ejemplo en este punto los casos de ironía; más allá de su dimensión como figura, en tanto alteración intencional para afirmar lo contrario de lo que se dice expresamente, hay un cierto consenso, impulsado desde la pragmática, en considerarla como un acto lingüístico reflexivo o como enunciado ecoico. Por un lado, la ironía presenta una relación en el eje lengua$\mathrm{je} /$ realidad, en la media en que se establece una distancia entre lo dicho y lo que se designa; pero también crea una relación entre los interlocutores (inclusión/exclusión en función de la intercomprensión), y una evocación, esto es, relaciones sígnicas con la situación, con otros textos, etc. En este sentido, en la medida en que la ironía pone sobre el tapete una relación funcional explícita con el texto como signo, se trata de un fenómeno metadiscursivo.

Un avance de los estudios sobre el metalenguaje en el ámbito de lo metadiscursivo se presenta en los estudios de metapragmática (Lucy, 1993). A mi juicio, se trata sin más de considerar, más allá de las propiedades sígnicas del signo usado, la dimensión de uso o pragmática del metalenguaje, esto es, las propiedades que en el discurso se producen después de la objetivación del lenguaje mismo.

\section{RECAPITULACIÓN}

En definitiva, para acercarnos ya a la clasificación de los hechos, podemos advertir que existen manifestaciones de lo metalingüístico en los tres niveles fundamentales del lenguaje: universal, 
histórico e individual. Hay hechos metalingüísticos universales (por ejemplo, la posibilidad de que el lenguaje sea objeto del lenguaje, como en el caso del uso metalingüístico del lenguaje primario), o hechos universales por lo que comportan de cognitivos, como la etimología popular o la metáfora (en ambos casos se trata de la modificación consciente de signos lingüísticos); hay hechos de metalengua (hechos condicionadas 'en' y 'desde' los idiomas, alojados en el léxico, como unidades simples o como fraseología, o en la gramática, ya sea oracional o supraoracional); y hay, finalmente, hechos de metahabla, o más exactamente, hechos metadiscursivos, en las ironías, en los ecos (diversos hechos reflexivos, sintagmáticos o paradigmáticos), o en los contenidos de discursos en los que se 'habla sobre' el lenguaje, como se observa en la Figura 4:

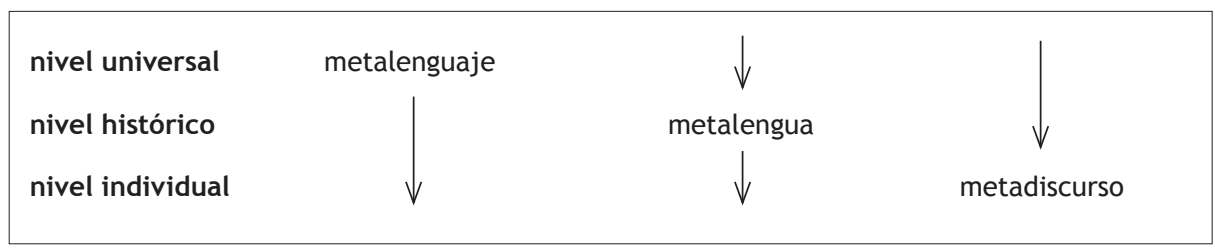

Figura 4. La clasificación del metalenguaje (I).

Si consideramos la distinción entre el 'hacer con' el lenguaje (= todos los fenómenos reflexivos que muestran el lenguaje, las lenguas y los textos como capacidad) y el 'decir del' lenguaje (= las predicaciones que se hacen sobre lo lingüístico) el esquema se completa del modo que sigue:

\begin{tabular}{|c|c|c|}
\hline 'decir del’ lenguaje & 'hacer con' el lenguaje & \\
\hline \multirow[t]{2}{*}{ lo lingüístico como objeto } & uso metalingüístico del lenguaje primario & $\begin{array}{c}\text { nivel } \\
\text { universal }\end{array}$ \\
\hline & $\begin{array}{l}\text { - gramática del ‘uso metalingüístico’ } \\
\text { - metalenguaje en el texto (= texto como nivel de } \\
\text { - estructuración idiomática) } \\
\text { - léxico metalingüístico } \\
\text { fraseología metalingüística (contenido y } \\
\text { gramática) }\end{array}$ & $\begin{array}{c}\text { nivel } \\
\text { histórico }\end{array}$ \\
\hline $\begin{array}{l}\text { - textos singulares en } \\
\text { los que se habla del } \\
\text { lenguaje } \\
\text { - refranes metalingüísticos }\end{array}$ & $\begin{array}{l}\text { hechos, estrategias, procedimientos y mecanismos } \\
\text { metadiscursivos: reformulación, atenuación, } \\
\text { intensificación, intertextualidad... (pueden estar } \\
\text { específicamente regulados en la gramática de una } \\
\text { lengua) }\end{array}$ & $\begin{array}{c}\text { nivel } \\
\text { individual }\end{array}$ \\
\hline
\end{tabular}

Figura 5. La clasificación del metalenguaje (II). 
En este artículo quise esbozar el objeto y los objetivos (amén de los resultados y de los caminos en vías de exploración) de una línea de trabajos desarrollada desde hace varios años (Loureda, 2001). Desde las indagaciones iniciales se advirtió que lo metalingüístico constituye un espacio del lenguaje, de las lenguas y del hablar con una compleja casuística. Por eso intenté establecer, primero, una tipología del metalenguaje que permitiera, después, describir cada una de sus manifestaciones en las lenguas (en particular, en el español). Las líneas que aquí terminan vuelven sobre el viejo tema, para ajustar algunas afirmaciones iniciales, pero también para resaltar la importancia de distinguir los tipos de metalenguaje con arreglo a su funcionamiento. Al fin y al cabo, el metalenguaje constituye un espacio determinante de nuestro comportamiento lingüístico: determinante desde el punto de vista cognitivo, idiomático y pragmático.

\section{REFERENCIAS BIBLIOGRÁFICAS}

Aznárez, M. (2006). La fraseología metalingüística con verbos de lengua en español actual. Francfort: Peter Lang.

Briz, A. (1998). El español coloquial en la conversación. Esbozo de pragmagramática. Barcelona: Ariel.

Bühler, K. (1967). Teoría del lenguaje. Revista de Occidente. Madrid.

Carnap, R. (1934). Logische Syntax der Sprache. Viena: Springer.

Castillo, C. (1998). Función metalingüística, metalenguaje y autonimia. Lexis, 22(2), 243-266.

Castillo, C. (2001). Contribución a un estudio diacrónico del sistema metalingüístico en las gramáticas del español. En M. Maquieira \& M. González (Eds.), Actas del III Congreso de la Sociedad Española de Historiografía Lingüística (pp. 293-301). Madrid: Arco Libros.

Castillo, C. (2005). La gramática de las unidades autónimas del español. En M. Casado, R. González \& O. Loureda (Eds.), Lo metalingüístico en español (pp. 273-292). Francfort: Peter Lang.

Coseriu, E. (1973). Teoría del lenguaje y lingüística general. Madrid: Gredos.

Coseriu, E. (1981). Lecciones de lingüística general. Madrid: Gredos.

Coseriu, E. (1987). Gramática, semántica, universales. Madrid: Gredos.

Coseriu, E. (1992). Competencia lingüística. Madrid: Gredos.

Coseriu, E. (2007). Lingüística del texto. Introducción a la hermenéutica del sentido. Madrid: Arco Libros.

de Shyreswood, G. (1937). Die Introductiones in logicam des Wilhelm von Shyreswood. Münich: Verlag der Bayerischen Akademie der Wissenschaften.

Dimter, M. (1981). Textklassenkonzepte heutiger Alltasgsprache. Kommunikationssituation, Textfunktion und Texttinhalt als Kategorien alltagsprachlicher Textklassifikation. Tubinga: Niemeyer. 
Escobedo, A. (1992). El campo semántico 'hablar’ en español. Granada: Universidad de Granada.

Fernández Bernárdez, C. (2002). Expresiones metalingüísticas con el verbo decir. La Coruña: Universidad.

Gutiérrez Ordóñez, S. (1997). Del uso metalingüístico. En S. Gutiérrez Ordóñez (Ed.), Principios de sintaxis funcional (pp. 381-393). Madrid: Arco Libros.

Hjelmslev, L. (1971). Prolegómenos a una teoría del lenguaje. Madrid: Gredos.

Jakobson, R. (1984). Ensayos de lingüística general. Barcelona: Ariel.

Kabatek, J. (2000). Os falantes como lingüistas. Tradición, innovación e interferencias no galego actual. Vigo: Xerais.

Lara, L. (2001). Ensayos de teoría semántica. México: El Colegio de México.

Loureda, 0. (2001). Del metalenguaje y sus tipos (con especial referencia a los modos de significar). Quaderni di Semantica, 21(2), 287-333.

Loureda, O. (2003). Los nombres de los tipos de texto. El campo léxico 'lo que se dice' en el español actual. Pamplona: EUNSA.

Loureda, 0. (2006). Tesis sobre el uso metalingüístico del lenguaje primario. En M. Casado, M. A. Esparza \& R. González (Eds.), Discurso lengua y metalenguaje. Balance y perspectivas (pp. 139-153). Hamburgo: Buske.

Lucy, J. (1993). Reflexive language: Reported speech and metapragmatics. Cambridge: Cambridge University Press.

Manero, E. (2005). Aproximación a un estudio del refrán. El refranero español de contenido metalingüístico. Pamplona: Universidad de Navarra.

Quine, W. (1968). Palabra y objeto. Barcelona: Labor.

Rey-Debove, J. (1997). Le métalangage. París: Armand Colin.

Rivarola, J. (1991). Signos y significados. Ensayo de semántica lingüística. Lima: Pontificia Universidad Católica del Perú.

San Agustín (1970). De Magistro. En K. D. Daur (Ed.), Aurelii Augustini Opera. Turnholti: Brepols.

Tarski, A. (1944). The semantic conception of truth and the foundations of semantics. Philosophy and Phenomenological Research, 4, 341-376.

Ulrich, M. (1997). Die Sprache als Sache: Primärsprache, Metasprache, Übersetzung: Untersuchungen zum Übersetzen und zur Übersetzbarkeit anhand von deutschen, englischen und vor allem romanischen Materialen. Tubinga: Gunter Narr.

Urban, W. (1952). Lenguaje y realidad. La filosofía del lenguaje y los principios del simbolismo. México: Fondo de Cultura Económica.

Vigara, A. (1992). Función metalingüística y uso del lenguaje. Epos, 8, 123-142. 
Wierzbicka, A. (1987). English speech act verbs. A semantic dictionnary. Sydney: Academic Press.

\section{NOTAS}

1 Las lenguas pueden tener procedimientos específicos (= una gramática) para la inserción e identificación en el hablar de tales hechos. En este sentido, partiendo de los niveles del lenguaje -universal, histórico, individual-, Coseriu (2007) distingue dos conceptos de texto: el texto como nivel autónomo de lo lingüístico y el texto como nivel de estructuración idiomática superior a la oración. Esta distinción funcional, añade, exige dos disciplinas distintas: una lingüística del nivel histórico, la gramática del texto, que estudie los procedimientos estrictamente idiomáticos para la construcción de los textos y una disciplina del nivel individual, una lingüística del texto capaz de revelar y justificar el sentido de todos los discursos. Coseriu (2007) entiende, pues, que la lingüística del texto no coincide en absoluto con la sintaxis que va más allá de la oración, nacida para describir tres tipos de hechos: los que pueden extenderse a lo largo de varias oraciones (como las citas o las enumeraciones), los que son característicos de una determinada clase de texto (como la elipsis en los telegramas o en los SMS) y los que funcionan en la oración pero apuntan más allá de sus límites (como los mecanismos de cohesión).

2 Como dice Lara (2001: 98), “un 'metalenguaje' es, para los lógicos que siguen a Hilbert y a Tarski, un lenguaje cuya única finalidad y función es fundamentar el valor de verdad de las proposiciones que se hagan con un determinado 'lenguaje-objeto', sea este la matemática (Hilbert) o cualquier otro lenguaje científico (Tarski \& Carnap); en segundo lugar, el 'metalenguaje' es una construcción controlada que define lo que puede tener sentido en el 'lenguaje-objeto' y las reglas con que se pueden producir proposiciones con sentido en él; en tercero, un 'metalenguaje' es 'esencialmente más rico' que su 'lenguaje-objeto', por cuanto contiene variables de un tipo lógico superior al de las variables de este".

3 Unas funciones del lenguaje que, por lo demás, se presentan como una extensión del modelo de órganon de Bühler (1967).

4 Sobre la idoneidad (o según el autor, sobre la falta de idoneidad) del adjetivo 'metalingüístico' aplicado al hablar sobre el lenguaje, en tanto que lenguaje de observación y descripción. Véase Lara (2001).

5 Sin embargo, continúa la discusión sobre cómo se construye el lenguaje de descripción (= secundario, convencional) de la lingüística o de disciplinas dependientes de la lingüística, como la lexicografía (por ejemplo, en Lara, 2001) o la gramática, pues constituyen 'metalenguajes' o modos de hablar científicos.

6 Carnap (1934) llamó 'autónimos' a los signos que se designan a sí mismos, opuestos a aquellos signos que designan las cosas ('heterónimos'). Quine (1968), desde el punto de vista lógico, introdujo la oposición entre 'uso' y 'mención' ('signos usados/signos mencionados').

7 Sigo mi exposición en Loureda (2001).

8 En la terminología de Coseriu (1987), se trata de un 'universal esencial'.

9 La reflexividad debe entenderse no como una propiedad del signo del que se habla, sino como una propiedad del discurso que habla del signo.

10 En la teoría de Bühler (1967) el signo es un hecho material que funciona en relación con el hablante, 
con el oyente y con los objetos. Con respecto a los objetos, la función del signo es la 'representación'.

11 Sobre la gramática y las propiedades de las unidades usadas metalingüísticamente en español, véase Gutiérrez Ordóñez (1997) y Castillo (1998, 2001, 2005); en francés, Rey-Debove (1997); y en alemán, Ulrich (1997), Rivarola (1991).

12 "El esfuerzo que un hablante-oyente hace al producir, formular, o, más aún, al intentar engarzar las partes de su discurso [...] queda plasmado en una serie de trazos que aparecen en este, y entre los que destacan los [...] marcadores metadiscursivos" (Briz, 1998: 201). Son "una especie de agarraderos de habla, cuya función, más que en manifestar una relación argumentativa (sin negar por ello que en ocasiones la expresen o participen de ella) consiste en servir de apoyo a los interlocutores para formular y reformular sus mensajes y al mismo tiempo para agarrar y ordenar las partes de los mismos" (Briz, 1998: 199-200). No se trata de un tipo de marcadores especial (de una mera nómina de unidades discursivas de cada idioma), sino, más bien, de una función de los marcadores: "más que un conector distinto del conector argumentativo, se trata de la segunda función general de los conectores pragmáticos: la formulativa, la de resolver problemas de formulación, la de relacionar las partes articuladas con el todo" (Briz, 1998: 204).

13 Sobre la fraseología metalingüística del español, remito al trabajo de Fernández Bernárdez (2002), que describe la fraseología construida sobre la base del verbo 'decir', y a la tesis de Aznárez (2006), que incluye consideraciones teóricas acerca de la fraseología metalingüística y una descripción del discurso repetido con los demás verbos de habla del español. 